\title{
AOR
}

Selected Papers of \#AolR2020:

The $21^{\text {st }}$ Annual Conference of the

Association of Internet Researchers

Virtual Event / 27-31 October 2020

\section{MOONWALKING: TRACING REDDITORS' DIGITAL MEMORY WORK ON MICHAEL JACKSON}

Marc Esteve Del Valle

Center for Media and Journalism Studies, University of Groningen

Rik Smit

Center for Media and Journalism Studies, University of Groningen

In this paper, we theoretically appropriate moonwalking to describe the memory work of Michael Jackson enthusiasts on the subreddit/r/MichaelJackson. Here, fans have been sharing thoughts, feelings, video clips, stories and photographs about the so-called King of Pop since the page's creation after his death in 2009. They have been engaging in discussions about Michael Jackson's private and public life and debating how this controversial celebrity should be remembered posthumously. The mnemonic practices of Redditors (Reddit users), we argue, share characteristics of Jackson's dance technique. On the one hand, people engaged in the public construction of Michael Jackson's memory go back in time. They use their own memories or archived content to emphasize particular elements of his public or private persona. On the other hand, they continually alter how he is remembered and forgotten, depending on the context of the present, which informs and shapes this process.

Working Michael Jackson's memory, therefore, comprises active practices that go back in time, while also going forward, constructing an ever-changing image of this star celebrity. This dialectic is at the heart of any type of mediated memory work, from personal diary writing, to journalistic remembrance and national commemorations (Van Dijck, 2007; Zelizer \& Tenenboim-Weinblatt, 2014). With the phrase mediated memory work, following Lohmeier and Pentzold (2014), we indicate the conscious and dynamic process of reconstructing the past in the present and moving it into the future through the use of media. This involves both individual efforts (only an individual is able to remember) and, what Halbwachs (1992) has called "the social frames of remembrance.", i.e. frames that are constituted by specific group dynamics and contexts, and by broader societal norms and values.

Suggested Citation (APA): Esteve Del Valle M., \& Smit, R. (2020, October). Moonwalking: Tracing Redditors' digital memory work on Michael Jackson. Paper presented at AolR 2020: The $21^{\text {th }}$ Annual Conference of the Association of Internet Researchers. Virtual Event: AolR. Retrieved from http://spir.aoir.org. 
These theoretical observations are empirically assessed by a content analysis of mnemonic comments and replies $(\mathrm{N}=917)$ posted on the subreddit/r/MichaelJackson. To collect our comments and replies, we wrote a crawler using Python and the Python Reddit API Wrapper (PRAW) library (Boe, 2020). In total, we collected 20,431 comments and replies posted between June 25, 2009 (the day the subreddit was created) and December 31,2018 . The sampling process was intended to locate those comments and replies reflecting mnemonic activity. To do so, we employed a purposive sampling method, also referred to as judgmental sampling or expert sampling (Battaglia, 2008). By using this sampling method, we collected all the comments and replies posted in the subreddit r/MichaelJackson containing the following words: 'remember*', 'death', 'memory', 'past', 'anniversary', 'birthday', and 'forget*' (the asterisk indicates multiple endings of the word). This resulted in a final sample of 917 comments and replies. The selection of sampling keywords was based on concepts frequently discussed in studies on celebrity commemoration (cf. Davies, 2012). Next, we captured Redditors' layered, messy and complex digital memory work through a content analysis of 917 comments and replies. The coding manual is based on the previously discussed works on the relationship between (social) media, memory and celebrity, specifically MJ (Burgess, Mitchell \& Münch, 2019; Davies, 2012). Redditors' comments and replies comprised the unit of analysis. The reliability scores of all the categories (except for 'The King of Pop' category -0.55-) range between high intercoder reliability (1) and a value of 0.62 which is an acceptable level (Viera \& Garrett, 2005). For exploratory studies like ours, these alphas are considered reliable enough to draw out and develop cautionary conclusions.

Our data reveals the existence of 370 individual posters who posted 510 comments and 407 replies related to the memory of Michael Jackson in the subreddit $/ \mathrm{r} /$ MichaelJackson. Within our sample, 533 posts were labeled as having at least one mnemonic dimension. That is, $58.12 \%$ of the posts in our sample engaged in some form of memory work, which we defined as the conscious and dynamic process of reconstructing the past in the present by means of assembling historic facts, sharing personal memories, or otherwise aiming to stabilize Michael Jackson's memory. When Redditors' engage in memory work, they are mostly sharing information about MJ's persona $(23.37 \%)$, immediately followed by posts and comments containing personal memories related to $\mathrm{MJ}(21.68 \%)$. Only $4.19 \%$ of the comments and replies in our sample were labeled as Meta-memory, those posts that are concerned with how MJ should be remembered.

More granularly, regarding the dimension 'MJ's Persona', our results show that the majority of the Redditors' comments and replies are about MJ as being the 'King of Pop' $(7.73 \%)$. These are closely followed by the comments and replies about MJ death (6.64 $\%)$ and physical appearance $(6.26 \%)$. Indeed, our analysis shows few comments on MJ's beneficence $(3.96 \%)$ and child abuse $(3.87 \%)$. Concerning the dimension 'Personal Memories', our results reveal that Redditors' online memories are clearly linked to Redditors' personal memories about MJ's recorded music $(9.42 \%)$, followed by their memories on MJ's death $(4.9 \%)$ and scandals (3\%). Finally, for the dimension 'Meta-memory', our data shows $2.4 \%$ of the comments and replies to be related to MJ's 
music and dance. These are followed by $1.53 \%$ of comments and replies about MJ's as an individual. And only $0.27 \%$ of comments and replies refer to $\mathrm{MJ}$ as a celebrity.

The empirical part of this paper supports the theoretical observation that individual attempts to stabilize the memory on Michael Jackson are leading to its dynamic nature. This dialectic is at the heart of any type of memory work, but it is amplified by this subreddit's community of memory. Importantly, though, we found that Redditors are not so much concerned with how Michael Jackson should be remembered, but rather how he is remembered by them individually. The community of memory emerging around MJ on this subreddit, then, revolves around the practice of sharing personal thoughts, memories and feelings concerning MJ and less so on settling on a fixed memory of him. It is a community, though, since Redditors seem genuinely interested in each other's stories, and are coming together on the subreddit to seek out each other's personal stories, which go back in time, but simultaneously forward; Redditors are moonwalking, together.

\section{References}

Battaglia, M. (2008). Purposive sample. In Encyclopedia of Survey Research Methods (Ed. Paul J. Lavrakas) (pp. 645-647).

Boe, B. (2020). PRAW: The Python Reddit API wrapper. Retrieved from: https://praw.readthedocs.io/en/latest/

Burgess, J., Mitchell, P., \& Münch, F.V. (2019). Social media rituals: The uses of celebrity death in digital culture. In Z. Papacharissi (Ed.), A networked self and birth, life, death (pp. 224-239). New York: Routledge.

Davies, C. (2012). No mere mortal? Re-materialising Michael Jackson in death. Celebrity Studies,3(2), 183-196.

Halbwachs, M. (1992). On collective memory. (L. Coser, Trans.). Chicago: U of Chicago Press.

Kitch, C. (2000). "A news of feeling as well as fact": Mourning and memorial in American news magazines, Journalism, 1(2), 171-195.

Lohmeier, C., \& Pentzold, C. (2014). Making mediated memory work: CubanAmericans, Miami media and the doings of diaspora memories. Media, Culture and Society, 36(6), 776-789. doi:10.1177/0163443713518574

Van Dijck, J. (2007). Mediated memories in the digital age. Stanford: Stanford University Press.

Zelizer, B. \& Tenenboim-Weinblatt, K., eds. (2014). Journalism and Memory. Houndmills, Basingstoke, Hampshire: Palgrave MacMillan 
